Chronic Obstructive Pulmonary Diseases: Journal of the COPD Foundation

\author{
Original Research
}

\title{
The Impact of Twice-Daily Indacaterol/Glycopyrrolate on the Components of Health-Related Quality of Life and Dyspnea in Patients with Moderate-to-Severe Chronic Obstructive Pulmonary Disease
}

Donald A Mahler, MD ${ }^{1}$ Edward Kerwin, $\mathrm{MD}^{2}$ Lindsey Murray, PhD, MPH ${ }^{3}$ Carole Dembek, $\mathrm{MS}^{4}$

\section{Abstract}

Background: Chronic cough, dyspnea, and excessive sputum production, the characteristic symptoms of chronic obstructive pulmonary disease (COPD), can negatively affect patients' health-related quality of life (HRQoL). The fixed-dose combination of a long-acting beta2-adrenergic agonist and a long-acting muscarinic antagonist (LABA/LAMA) have been shown to improve HRQoL and COPD symptoms as measured by the St George's Respiratory Questionnaire (SGRQ) and the Transition Dyspnea Index (TDI) total scores. However, the impact of a LABA/LAMA on the individual components of HRQOL and dyspnea with daily activities is unknown.

Methods: Secondary analysis of pooled data from 2 replicate, phase 3, 12-week, randomized, placebo, and active-controlled trials of twice-daily indacaterol/glycopyrrolate (IND/GLY) were analyzed. Change from baseline in HRQoL and dyspnea was measured by SGRQ and TDI, respectively. Total and component scores were evaluated using linear mixed models. Logistic regression was used to analyze the proportion of patients achieving minimum clinically important difference. Study outcomes were further explored in patient subgroups. Results: A total of 2038 patients from FLIGHT1/FLIGHT2 studies were evaluated. IND/GLY significantly improved SGRQ component scores (symptoms [-7.3], activity [-3.6], and impacts [-5.0]); all $P<0.001$ compared with placebo. IND/GLY also significantly improved symptoms scores compared with IND and GLY (-3.5 and -3.7 , respectively; both $P<0.001$ ). Patients treated with IND/GLY also had significant improvements in TDI component scores compared with placebo: functional impairment (0.48), magnitude of task (0.61), and magnitude of effort (0.54); all $P<0.001$. All component scores were significantly higher for IND/GLY compared with IND and GLY ( $P \leq 0.002$ for all).

Conclusions: Twice-daily IND/GLY significantly improved total scores as well as components of HRQDL and dyspnea in patients with COPD. These data demonstrate multiple clinical benefits of LABA/LAMA maintenance therapy in the COPD population.

ClinicalTrials.gov: NCT 01727141 and NCT 01712516

\footnotetext{
Abbreviations: chronic obstructive pulmonary disease, COPD; health-related quality of life, HRQoL; long-acting muscarinic antagonist, LAMA; long-acting beta2-adrenergic agonist, LABA; St George's Respiratory Questionnaire, SGRQ; Transition Dyspnea Index, TDI; indacaterol, IND; glycopyrrolate, GLY; indacaterol/glycopyrrolate, IND/GLY; Global initiative for chronic Obstructive Lung Disease, GOLD; twice daily, BID; fixed-dose combination, FDC; forced expiratory volume in 1 second, FEV 1 ; forced vital capacity, FVC; modified Medical Research Council dyspnea scale, mMRC; inhaled corticosteroid, ICS; short-acting beta2-agonist, SABA; minimum clinically important difference, MCID; Baseline Dyspnea Index, BDI; odds ratio, OR; confidence interval, CI; least squares, LS; standard deviation, SD; standard error, SE

Funding Support: Sunovion Pharmaceuticals Inc., provided funding for this research.

Date of Acceptance: July 19, 2019
} 
Citation: Mahler DA, Kerwin E, Murray L, Dembek C. The impact of twice-daily indacaterol/glycopyrrolate on the components of healthrelated quality of life and dyspnea in patients with moderate-to-severe chronic obstructive pulmonary disease. Chronic Obstr Pulm Dis. 2019;6(4):308-320. doi: https://doi.org/10.15326/jcopdf.6.4.2019.0131

$\frac{1 \text { Geisel School of Medicine at Dartmouth, Hanover, New Hampshire }}{2 \text { Clinical Research Institute of Southern Oregon, Medford, Oregon }}$

3 Evidera, Bethesda, Maryland

4 Sunovion Pharmaceuticals Inc., Marlborough, Massachusetts

\section{Address correspondence to:}

Carole Dembek

Sunovion Pharmaceuticals Inc.

84 Waterford Drive

Marlborough, MA 01752

Phone: +1 508-357-7704

Email: carole.dembek@sunovion.com

\section{Keywords:}

indacaterol/glycopyrrolate, chronic obstructive pulmonary disease, St George's Respiratory Questionnaire, Transition Dyspnea Index, health-related quality of life

\section{Introduction}

Chronic obstructive pulmonary disease (COPD) is a common disorder and leading cause of morbidity and mortality. In the United States, COPD affects nearly 30 million people and is the fourth leading cause of death. ${ }^{1,2}$ The economic burden of COPD is considerable with national medical costs projected to increase from $\$ 32.1$ billion in 2010 to $\$ 49.0$ billion by $2020 .^{3}$

COPD is characterized by airflow limitation and persistent respiratory symptoms, including dyspnea, chronic cough, and excessive sputum production. ${ }^{4}$ In addition, patients with COPD commonly experience exacerbations, i.e., acute worsening of COPD symptoms that require additional therapy. ${ }^{4}$ Studies have found COPD to be associated with increased activity limitations, e.g., walking, bathing, etc., inability to work, and fatigue, which can profoundly diminish health-related quality of life (HRQoL). ${ }^{5-11}$

While COPD is not curable, pharmacologic therapy is recommended to reduce symptoms, improve health status, and reduce the risk and severity of exacerbations. ${ }^{4}$ The 2019 report of the Global initiative for chronic Obstructive Lung Disease (GOLD) 4 recommends the use of one or more long-acting bronchodilators for maintenance therapy of COPD. Indacaterol/glycopyrrolate 27.5/15.6 $\mathrm{gg}$ (IND/GLY) is a twice-daily (BID) long-acting beta2-adrenergic agonist/long-acting muscarinic antagonist (LABA/ LAMA) fixed-dose combination (FDC) indicated for the long-term maintenance treatment of airflow limitation in patients with COPD. ${ }^{12}$

The safety and efficacy of IND/GLY were established in FLIGHT1 (ClinicalTrials.gov identifier: NCT 01727141) and FLIGHT2 (NCT 0171251) studies, two 12-week, replicate, multicenter, randomized, double-blind, parallel-group, placebo- and activecontrolled studies that evaluated IND/GLY 27.5/15.6 $\mu \mathrm{g}$ compared with the respective monotherapies and placebo in patients with moderate-to-severe COPD. ${ }^{13}$ In addition, IND/GLY significantly improved HRQOL and dyspnea as measured by St George's Respiratory Questionnaire (SGRQ) and Transition Dyspnea Index (TDI), respectively, and reduced rescue medication use compared with placebo. Five LABA/LAMA FDCs are approved for the treatment of COPD in the United States:IND/GLY, umeclidinium/vilanterol,tiotropium/ olodaterol, GLY/formoterol, and aclidinium/ formoterol. ${ }^{12,14-17}$ All have demonstrated statistically significant improvements in SGRQ total score and responder rates compared with placebo. ${ }^{13,18-21}$ However, the impact of LABA/LAMA on the individual components of the SGRQ and TDI is unknown. As each component measures different aspects of the effect of COPD on patients' overall quality of life, it is important to know the individual contribution of each component to the overall improvement in the HRQOL and dyspnea. This paper reports the effect of IND/GLY 27.5/15.6 $\mathrm{kg}$ on SGRQ and TDI component scores from an analysis of pooled data from the FLIGHT 1 and FLIGHT2 studies.

\section{Methods}

\section{Data Source}

Secondary analysis of pooled data from the multinational FLIGHT1 and FLIGHT2 studies was conducted. Both studies were approved by institutional review boards or ethics committees at participating centers and were conducted in accordance with the International Conference on Harmonization and the Declaration of Helsinki. Informed consent was 
obtained from all patients.

\section{Inclusion/Exc/usion Criteria}

FLIGHT1 and FLIGHT2 included male and female patients $\geq 40$ years of age with stable but symptomatic moderate-to-severe COPD as per the GOLD 2011 criteria. $^{22}$ Inclusion criteria included postbronchodilator forced expiratory volume in 1 second $\left(F E V_{1}\right) \geq 30 \%$ and $<80 \%$ of predicted normal, a postbronchodilator $\mathrm{FEV}_{1} /$ forced vital capacity $(\mathrm{FVC})<0.70$, smoking history of at least 10 pack years and modified Medical Research Council dyspnea scale (mMRC) grade $\geq 2$. Additional information on patient inclusion and exclusion criteria has been published elsewhere. ${ }^{13}$

\section{Study Design}

The design of the FLIGHT studies is presented in Figure 1. Patients meeting the eligibility criteria were randomized (1:1:1:1) to IND/GLY (27.5/15.6 $\mu \mathrm{g}$ BID), IND monotherapy (27.5 $\mu$ g BID), GLY monotherapy (15.6 $\mu$ g BID), or placebo BID. The Neohaler ${ }^{\circledR}$ device (Novartis Pharma, AG, Basel, Switzerland) was used to deliver all treatments throughout the 12-week study period. It is important to note that outside the United States, IND/GLY is available as a once-daily formulation of indacaterol $110 \mu \mathrm{g}$ and glycopyrronium $50 \mu \mathrm{g}$. As such, the findings from our analysis only apply to the United States IND/GLY 27.5/15.6 $\mu \mathrm{g}$ formulation. Treatment assignment was concealed from patients, investigator staff, and the study sponsor during the treatment period. Enrolled patients were permitted to continue background inhaled corticosteroid (ICS) therapy. Patients taking an FDC of an LABA and ICS discontinued LABA/ICS therapy and switched to an equivalent ICS at least 48 hours before the start of the run-in period, all patients were provided with a short-acting beta2-adrenergic agonist ([SABA] salbutamol or albuterol) for use as a rescue inhaler on an "as needed" basis.

\section{St George's Respiratory Questionnaire}

The SGRQ is a validated, COPD-specific, selfadministered, patient-reported outcome instrument designed to measure HRQoL. The questionnaire contains 50 items with 76 weighted responses and consists of 3 components: symptoms, activity, and impacts. ${ }^{23,24}$ The symptoms component includes 8 items concerned with severity and frequency of respiratory symptoms such as cough, sputum production, breathlessness, and wheeze, and duration and frequency of breathlessness or wheeze. The activity component consists of 16 items related to daily physical activities that either lead to or are limited by breathlessness, while the impacts component includes 26 items related to social functioning and psychological disturbances resulting from airway

\section{Figure 1. FLIGHT1 and FLIGHT2 Study Design}

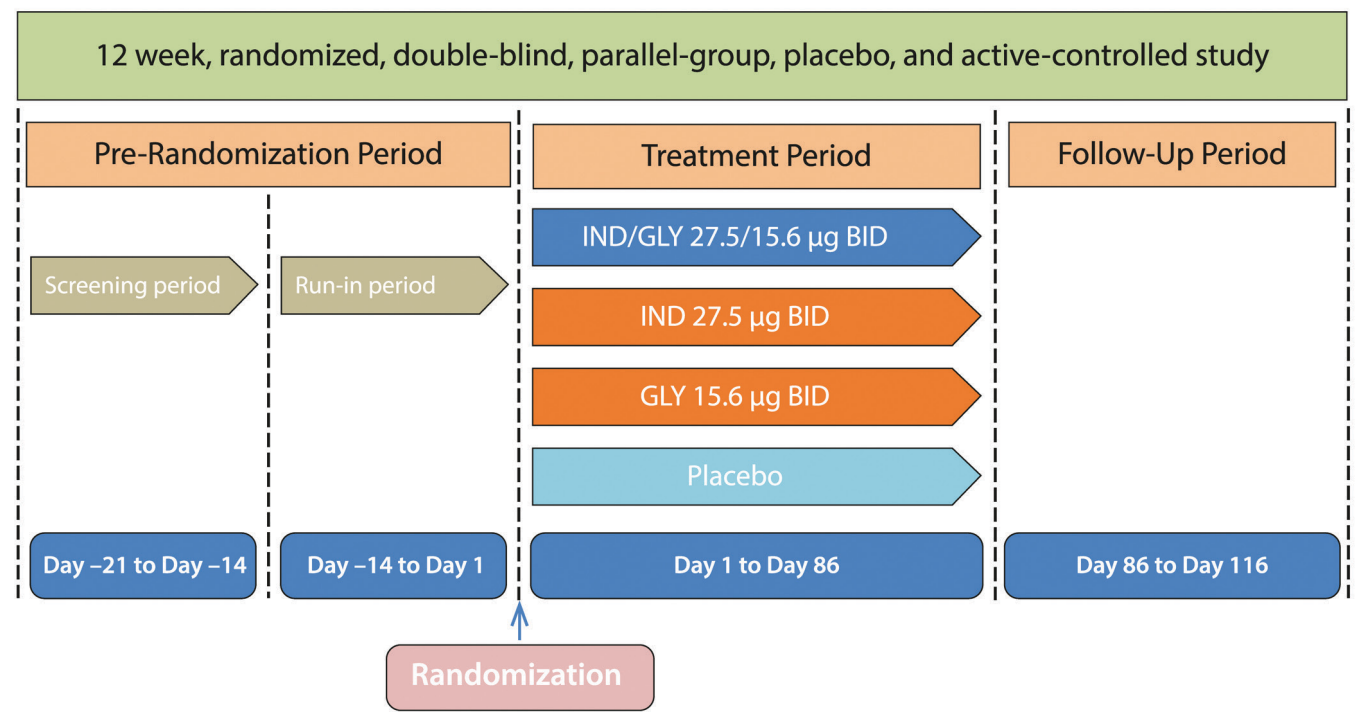

$\mathrm{BID}=$ twice daily; IND=indacaterol; GLY=glycopyrrolate 
disease. Each component is scored from 0 to 100 with lower scores indicating less impairment. A total score is calculated by summing all items and ranges from 0 to 100. Thus, component scores are not additive to the total score. The minimum clinically important difference (MCID) is a 4-unit or more improvement (reduction) in SGRQ total score. ${ }^{24}$ There is no MCID established for the components of SGRQ. In the FLIGHT studies, SGRQ was administered at baseline and week 12 and, if applicable, at the time of treatment discontinuation. The change from baseline at week 12 and responder rate (the percentage of patients achieving MCID in the total score) were evaluated as key secondary endpoints.

\section{Baseline Dyspnea Index and Transition Dyspnea Index}

The Baseline Dyspnea Index (BDI) and TDI are validated patient-reported measures of dyspnea related to activities of daily living. ${ }^{25-27}$ The BDI measures the severity of dyspnea at baseline and TDI measures change from baseline. These indices consist of 3 components: functional impairment, magnitude of task, and magnitude of effort required to evoke dyspnea. Each component is scored from -3 (major deterioration) to +3 (major improvement) with total TDI scores ranging from -9 (major deterioration) to +9 (major improvement). There is no MCID established for the components of the TDI. An increase of 1 or more units of TDI has been established as the MCID for the TDI total score. ${ }^{28}$ In the FLIGHT studies, BDI was administered at baseline and TDI was administered at week 12 by a site staff member or at the time of discontinuation for patients who discontinued prematurely. The TDI total score was evaluated as a secondary endpoint in FLIGHT 1 and FLIGHT2 studies.

\section{Statistical Analysis}

All randomized patients who received at least 1 dose of treatment were included in the analysis of pooled data from FLIGHT 1 and FLIGHT2 studies following the intent to treat principle. Linear mixed models were used to analyze change from baseline at week 12 in each component score of SGRQ or individual TDI component score at week 12 as response variables, while treatment was a primary independent variable. Each mixed model included treatment, study, treatment and study interaction, baseline component score, smoking status at baseline, baseline ICS use, and region as fixed effects and center nested within region nested within study as random effect. The missing data at week 12 were imputed with last observation carried forward if measurement was conducted after 4 weeks of treatment. Each component of SGRQ or TDI was evaluated as part of post hoc analyses to better characterize response by subgroups of clinical interest: age ( $<65,65$ to $<75, \geq 75$ years), gender (male/ female), severity of airflow obstruction (GOLD Grade 2 or moderate [baseline post-bronchodilator $\mathrm{FEV}_{1}$ between $50 \%$ and $<80 \%]$ )/(GOLD Grade 3 or severe [baseline $\mathrm{FEV}_{1}$ between $30 \%$ and $<50 \%$ ]), smoking status (current/ex-smoker), ICS use at baseline (yes/ no), FEV 1 reversibility (reversible/not reversible), and 2011 GOLD combined risk assessment (Group B/Group D). Logistic regression was used to analyze the proportion of responders (i.e., patients achieving published MCID score thresholds for SGRQ and TDI) across different patient subgroups and odds ratio (OR) along with 95\% confidence interval (CI) were reported. The level of significance was set to 0.05 without adjustment for multiplicity. All analyses were conducted using SAS 9.3 (SAS Institute, Cary, North Carolina).

\section{Results}

\section{Patient Disposition and Characteristics}

In FLIGHT1 and FLIGHT2, 2043 patients were randomized to IND/GLY ( $\mathrm{n}=510)$, IND ( $\mathrm{n}=511$ ), GLY $(n=512)$, or placebo $(n=510)$. For the individual studies, patient disposition and demographic and clinical characteristics have been reported by Mahler et al. ${ }^{13}$ For the pooled studies, demographic and clinical characteristics of patients by treatment group are shown in Table 1 . Briefly, $>88 \%$ of patients were white, approximately half were current smokers, the average $\mathrm{FEV}_{1} \%$ predicted was $54 \%$, the percentage using concurrent ICS at baseline ranged from 43\%$50 \%$, and approximately $30 \%$ of patients reported 1 or more COPD exacerbations in the previous year.

\section{St George's Respiratory Questionnaire Component Scores}

Compared with placebo, patients treated with IND/ GLY demonstrated significant improvements $(P<$ 0.001) in all SGRQ component scores at week 12, with least squares (LS) mean (95\% CI) of -7.25 (-9.30 


\section{Table 1. Demographic and Clinical Characteristics of Patients From Pooled FLIGHT1 and FLIGHT2 Data ${ }^{a}$}

Patient Characteristics
Indacaterol/

Glycopyrrolate $(\mathrm{n}=508) \mathrm{n}(\%)$

\author{
Indacaterol \\ $(n=511) n(\%)$
}

Glycopyrrolate

$(n=511) n(\%)$
Placebo

$(n=508) n(\%)$

\begin{tabular}{|c|c|c|c|c|}
\hline Age, years, mean (SD) & $63.4(8.60)$ & $63.7(8.32)$ & $63.4(8.40)$ & $63.2(8.12)$ \\
\hline Sex, male, n (\%) & 322 (63.4) & $336(65.8)$ & $326(63.8)$ & $306(60.2)$ \\
\hline \multicolumn{5}{|l|}{ Race, n (\%) } \\
\hline White & $470(92.5)$ & $463(90.6)$ & $451(88.3)$ & $469(92.3)$ \\
\hline Other & $38(7.5)$ & $48(9.4)$ & $60(11.7)$ & $39(7.7)$ \\
\hline Duration of COPD, years, mean (SD) & $7.1(6.01)$ & $7.0(5.27)$ & $7.0(5.46)$ & $7.1(5.37)$ \\
\hline \multicolumn{5}{|l|}{ COPD Severity, $\mathrm{n}(\%)$} \\
\hline Moderate (GOLD 2) & 313 (61.6) & $304(59.5)$ & 315 (61.6) & $305(60.0)$ \\
\hline Severe (GOLD 3) & $192(37.8)$ & 204 (39.9) & $191(37.4)$ & 199 (39.2) \\
\hline \multicolumn{5}{|l|}{ GOLD Classification, $\mathrm{n}(\%)$} \\
\hline GOLD B & $397(58.5)$ & $291(56.9)$ & $293(57.3)$ & $284(55.9)$ \\
\hline GOLD D & 208 (40.9) & $217(42.5)$ & $214(41.9)$ & $219(43.1)$ \\
\hline ICS Use at Baseline, $\mathrm{n}(\%)$ & $233(50.4)$ & $250(48.9)$ & $219(42.9)$ & $231(45.5)$ \\
\hline \multicolumn{5}{|l|}{ Smoking History, n (\%) } \\
\hline Ex-Smoker & 252 (49.6) & $245(47.9)$ & $244(47.7)$ & $246(48.4)$ \\
\hline Current Smoker & $256(50.4)$ & $266(52.1)$ & $267(52.3)$ & $262(51.6)$ \\
\hline \multicolumn{5}{|c|}{ Number of COPD Exacerbations in the Previous Year, n (\%) } \\
\hline $\mathbf{0}$ & $348(68.5)$ & $358(70.1)$ & $348(68.1)$ & $349(68.7)$ \\
\hline 1 & $132(26.0)$ & $118(23.1)$ & $124(24.3)$ & $121(23.8)$ \\
\hline$\geq 2$ & $28(5.5)$ & $35(6.8)$ & $39(7.6)$ & $38(7.5)$ \\
\hline \multicolumn{5}{|l|}{ SGRQ Score, mean (SD) } \\
\hline Total Score & $49.60(17.80)$ & $49.40(17.24)$ & $50.10(16.67)$ & $48.30(17.39)$ \\
\hline Symptoms & $60.15(21.30)$ & $59.56(21.93)$ & $61.19(20.54)$ & $60.56(21.91)$ \\
\hline Activity & $64.72(19.18)$ & $64.79(18.07)$ & $66.33(18.61)$ & $64.46(19.07)$ \\
\hline Impacts & $36.74(20.38)$ & $36.54(19.30)$ & $37.27(18.73)$ & $34.80(18.97)$ \\
\hline \multicolumn{5}{|l|}{ BDI Score, mean (SD) } \\
\hline Total Score & $5.83(1.95)$ & $5.86(1.80)$ & $5.76(1.84)$ & $5.92(1.93)$ \\
\hline Functional Impairment & $2.09(0.83)$ & $2.06(0.80)$ & $2.04(0.84)$ & $2.13(0.84)$ \\
\hline Magnitude of Task & $1.93(0.74)$ & $1.96(0.70)$ & $1.90(0.72)$ & $1.94(0.72)$ \\
\hline Magnitude of Effort & $1.83(0.74)$ & $1.84(0.67)$ & $1.83(0.66)$ & $1.88(0.70)$ \\
\hline \multicolumn{5}{|l|}{$\mathbf{F E V}_{\mathbf{1}}$, mean (SD) } \\
\hline Pre-Bronchodilator, $\mathrm{L}$ & $1.264(0.445)$ & $1.280(0.484)$ & $1.258(0.468)$ & $1.250(0.472)$ \\
\hline Post-Bronchodilator, L & $1.520(0.447)$ & $1.530(0.514)$ & $1.517(0.485)$ & $1.497(0.511)$ \\
\hline Post-Bronchodilator, $\% \mathrm{FEV}_{1}$ predicted & $54.9(13.33)$ & $54.4(13.48)$ & $54.6(13.18)$ & $54.4(13.14)$ \\
\hline FEV $_{1}$ Reversibility, $\%$ & $22.7(17.45)$ & $22.3(16.25)$ & $23.5(17.20)$ & $22.8(17.76)$ \\
\hline $\begin{array}{l}\text { FEV } \mathbf{1} \text { /FVC, mean (SD), } \\
\% \text { post-bronchodilator }\end{array}$ & $50.2(10.54)$ & $49.5(10.53)$ & $50.3(10.44)$ & $49.5(10.91$ \\
\hline
\end{tabular}

${ }^{a}$ full analysis set

$\mathrm{SD}=$ standard deviation; $\mathrm{COPD}=$ chronic obstructive lung disease; $\mathrm{GOLD}=\mathrm{Global}$ initiative for chronic Obstructive Lung Disease;

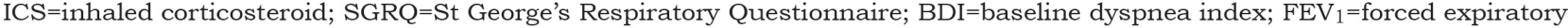
volume in 1 second; FVC=forced vital capacity 


\section{Figure 2. Change From Baseline in St George's Respiratory Questionnaire Total and Component Scores}

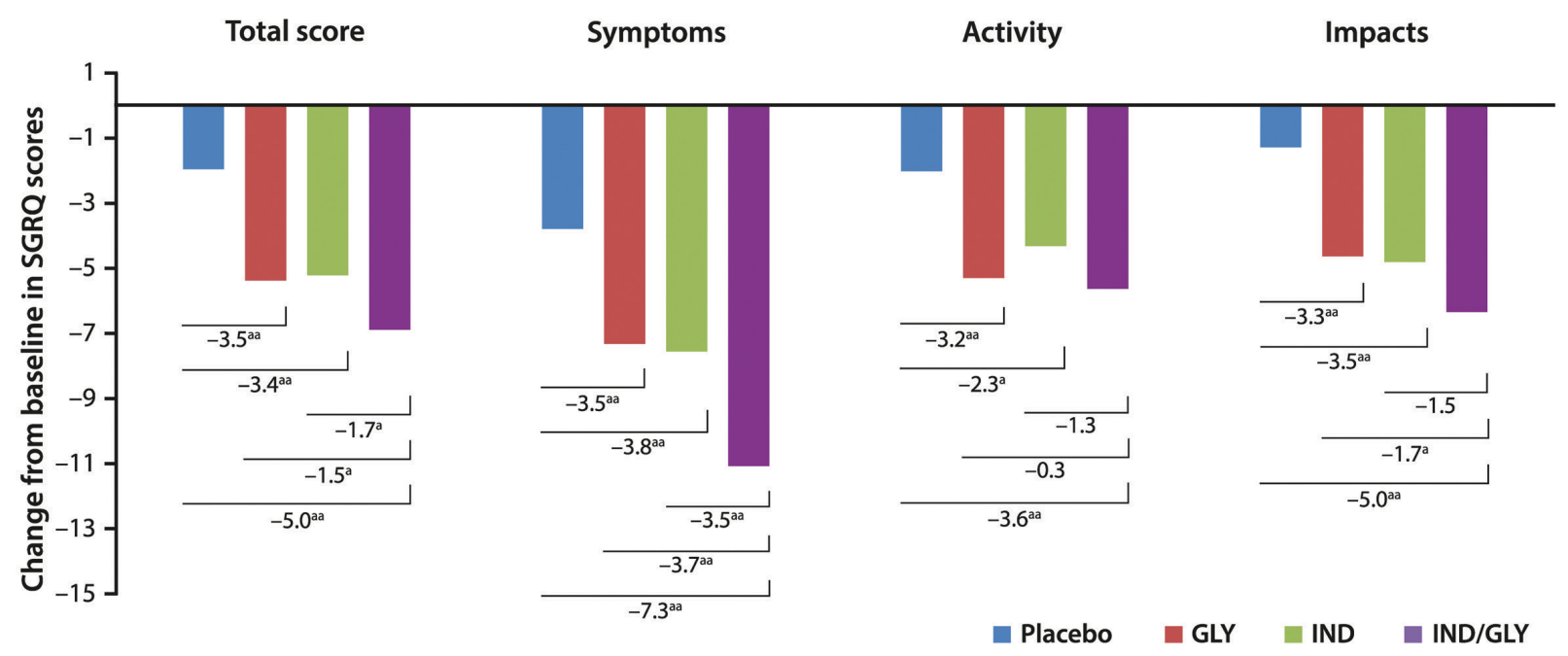

${ }^{\text {a }} P<0.05$

aa $P<0.001$

SGRQ=St George's Respiratory Questionnaire; GLY=glycopyrrolate; IND=indacaterol

to -5.21$)$ for symptoms, -3.57 ( -5.36 to -1.79$)$ for activity, and -5.01 ( -6.63 to -3.38 ) for impacts (Figure 2). Statistically significant improvements $(P<0.001)$ in the symptom component were also observed in patients treated with IND/GLY compared with IND -3.46 (-5.47 to -1.45$)$ or GLY -3.72 ( -5.74 to -1.70$)$. The improvements in activity and impacts components for IND/GLY compared with IND and GLY were not statistically significant.

In subgroup analyses, statistically significant improvements over placebo were observed for total score, and symptoms, activity, and impacts component scores in each subgroup, except for the subgroup of patients $\geq 75$ years old (Figure 3 ). The subgroups of patients with severe airflow limitation $\left(\mathrm{FEV}_{1}, 30 \%\right.$ to $<50 \%$ ), Group D classification by GOLD 2011 $\left(\mathrm{FEV}_{1}<50 \%\right.$ or 2 moderate exacerbations, or 1 hospitalization in the prior year), FEV 1 reversibility, or current smokers, consistently showed the greatest benefit of IND/GLY compared with placebo for the symptoms, activity, and impacts components. The respective LS means and 95\% CIs are shown in Figure 3. The treatment by subgroup interaction terms were statistically insignificant.

For all subgroups except those with age $\geq 75$ years, treatment with IND/GLY resulted in significantly increased odds of patients achieving MCID in the SGRQ total score compared with placebo, especially among patients with severe airflow limitation (OR [95\% CI], 3.87 [2.44-6.14]; $P<0.001)$ or Group D classification by GOLD 2011 (3.56 [2.30-5.51]; $P<$ 0.001; Figure 4). In addition, current smokers (2.65 [1.80-3.90]; $P<0.001)$ and those with reversible $\mathrm{FEV}_{1}$ (2.91 [2.01-4.22]; $P<0.001)$ showed the higher odds for improved SGRQ response. Patients under aged 65 years (2.85 [1.97-4.13]; $P<0.001)$, and females $(2.97$ [1.90-4.64]; $P<0.001)$ were more likely to achieve MCID in this analysis.

\section{TDI Component Scores}

Patients treated with IND/GLY were observed to have statistically significant improvements at week 12 ( $P$ $<0.001)$ in all 3 components of TDI compared with patients treated with IND, GLY, or placebo (Figure 5). At week 12, patients treated with IND/GLY demonstrated significant improvements in functional impairment compared with patients treated with IND (LS mean [95\% CI], 0.23 [0.10-0.36]; $P<0.001)$, GLY (0.20 [0.07-0.32]; $P=0.002)$, or placebo (0.48 [0.35-0.61]; $P<0.001)$. Results showed similar improvements for magnitude of task and magnitude of effort components ( $P<0.001$ for all comparisons). 


\section{Figure 3. Least Square Mean Differences in Change From Baseline in St George's Respirtory Questionnaire ${ }^{\mathrm{a}}$ in Indacaterol/ Glycopyrrolate Versus Placebo ${ }^{\text {b }}$}

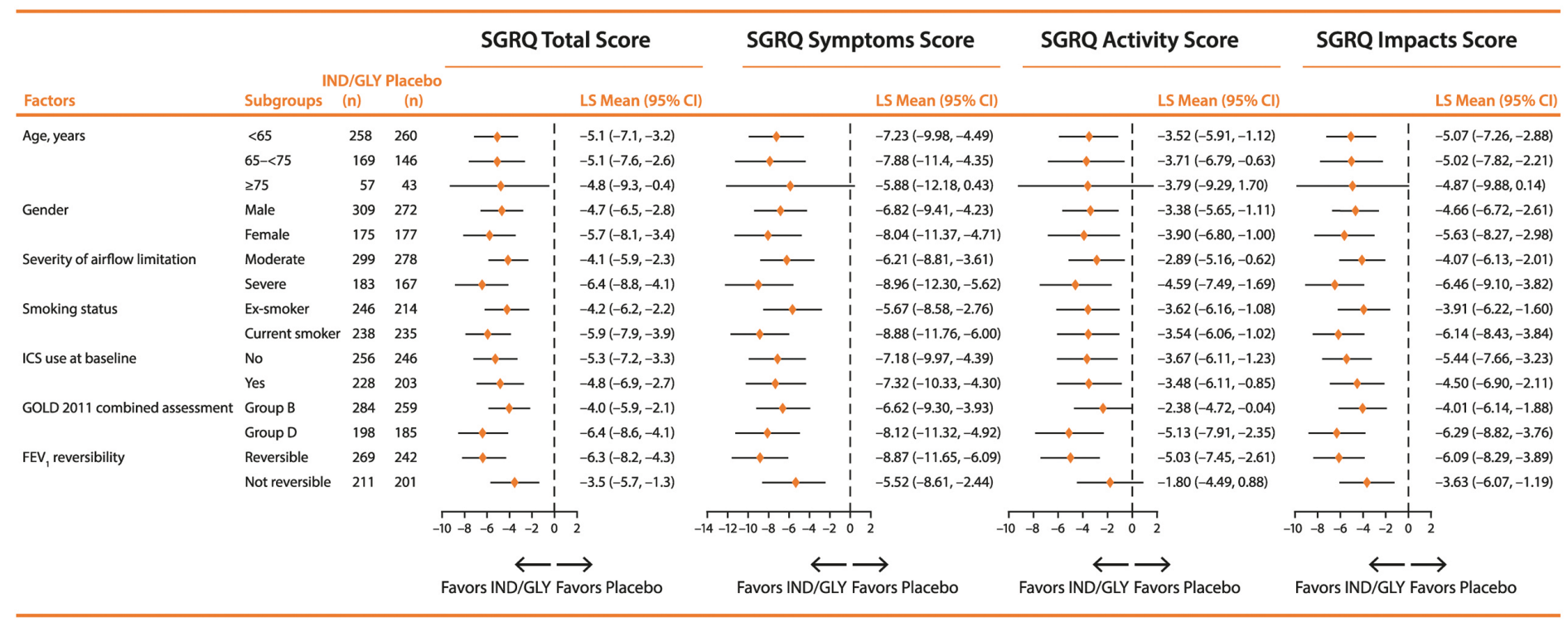

atotal and component scores at week 12

$b_{\text {among different patient subgroups }}$

$\mathrm{SGRQ}=$ St George's Respiratory Questionnaire; IND/GLY= indacaterol/glycopyrrolate; LS=least square; CI=confidence interval;

ICS=inhaled corticosteroids; GOLD=Global initiative for chronic Obstructive Lung Disease; FEV 1 =forced expiratory volume in 1 second

For all patient subgroups, treatment with IND/ GLY resulted in improvements in total TDI score when compared with placebo (Figure 6). Statistically significant improvements $(P<0.05)$ were observed for functional impairment, magnitude of task, and magnitude of effort components for each subgroup. The subgroups of patients with severe airflow limitation, Group D classification by GOLD 2011, or FEV 1 reversibility consistently showed the greatest benefit of IND/GLY compared with placebo; the respective LS means and 95\% CIs for total score, functional impairment, magnitude of task, and magnitude of effort are shown in Figure 6. The treatment by subgroup interaction terms were statistically insignificant.

For all patient subgroups, treatment with IND/GLY resulted in significantly increased odds of patients achieving MCID in the TDI total score compared with placebo (Figure 7), especially among patients with severe airflow limitation (OR [95\% CI], 3.15 [2.014.93]; $P<0.001)$ or Group D classification by GOLD 2011 (3.31 [2.15-5.10]; $P<0.001)$.

\section{Discussion}

In this pooled analysis of FLIGHT1/FLIGHT2, IND/ GLY significantly improved HRQoL and dyspnea as measured by components of SGRQ and TDI, respectively, in patients with moderate-to-severe COPD. In comparison to monotherapy, the dual bronchodilator showed significant improvement in the symptom component for HRQoL and all components for dyspnea.

To our knowledge, this is the first paper to present SGRQ and TDI component scores for a LABA/LAMA FDC. Pharmacologic treatment of COPD is intended to reduce symptoms and improve health status and exercise tolerance. ${ }^{4}$ The SGRQ consists of 3 components that measure different aspects of health status. The symptoms component primarily measures severity and frequency of respiratory symptoms, while the activity component measures daily physical activities that either lead to, or are limited by, breathlessness. The third component, impacts, measures social functioning and psychological 


\section{Figure 4. Odds Ratio for Achieving Minimum Clinically Important Difference in St George's Respiratory Questionnaire Total Score in Indacaterol/Glycopyrrolate Versus Placebo ${ }^{a}$}

\begin{tabular}{|c|c|c|c|c|c|c|}
\hline Factors & Subgroups & $\begin{array}{c}\text { GLY/IND } \\
\text { (n) }\end{array}$ & $\begin{array}{l}\text { Placebo } \\
\text { (n) }\end{array}$ & & & OR $(95 \% \mathrm{Cl})$ \\
\hline \multirow[t]{3}{*}{ Age, years } & $<65$ & 273 & 290 & $\longrightarrow$ & & $2.85(1.97,4.13)$ \\
\hline & $65-<75$ & 177 & 170 & - & & $2.28(1.43,3.64)$ \\
\hline & $\geq 75$ & 58 & 48 & $\frac{1}{1}$ & & $1.81(0.79,4.14)$ \\
\hline \multirow[t]{2}{*}{ Gender } & Male & 322 & 306 & $:-$ & & $2.26(1.60,3.19)$ \\
\hline & Female & 186 & 202 & $i$ & & $2.97(1.90,4.64)$ \\
\hline \multirow[t]{2}{*}{ Severity of airflow limitation } & Moderate & 313 & 305 & 一 & & $1.93(1.37,2.72)$ \\
\hline & Severe & 192 & 199 & $i$ & & $3.87(2.44,6.14)$ \\
\hline \multirow[t]{2}{*}{ Smoking status } & Ex-smoker & 252 & 246 & - & & $2.36(1.60,3.47)$ \\
\hline & Current smoker & 256 & 262 & 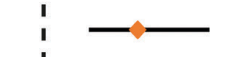 & & $2.65(1.80,3.90)$ \\
\hline \multirow[t]{2}{*}{ ICS use at baseline } & No & 275 & 277 & - & & $2.19(1.51,3.16)$ \\
\hline & Yes & 233 & 231 & $i$ & & $2.94(1.96,4.41)$ \\
\hline \multirow[t]{2}{*}{ GOLD 2011 combined assessment } & Group B & 297 & 284 & 1. & & $1.93(1.35,2.75)$ \\
\hline & Group D & 208 & 219 & 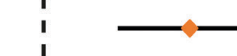 & & $3.56(2.30,5.51)$ \\
\hline \multirow{3}{*}{$\mathrm{FEV}_{1}$ reversibility } & Reversible & 279 & 272 & 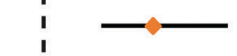 & & $2.91(2.01,4.22)$ \\
\hline & Not reversible & 222 & 228 & : - & & $2.12(1.41,3.21)$ \\
\hline & & & & $\begin{array}{llll}1 & 1 & 1 & 1 \\
1 & 2 & 3 & 4\end{array}$ & $\begin{array}{ll}1 & 1 \\
5 & 6\end{array}$ & 7 \\
\hline
\end{tabular}

a among different patient subgroups

IND/GLY=indacaterol/glycopyrrolate; OR=odds ratio; $\mathrm{CI}=$ confidence interval; ICS=inhaled corticosteroids; GOLD=Global initiative for chronic Obstructive Lung Disease; $\mathrm{FEV}_{1}=$ forced expiratory volume in 1 second

disturbances resulting from COPD. Our assessment of the SGRQ component scores revealed a significant improvement in the symptom component for IND/GLY compared with IND, GLY, and placebo. By contrast, the improvement in activity and impacts components was only significant for IND/GLY compared with placebo. These findings suggest that symptom improvement is the main driver of the HRQoL benefits of IND/GLY.

Our analyses of subgroups identified COPD patients likely to have the greatest overall SGRQ improvement with dual bronchodilation. Consistently, individuals with low FEV 1 (<50\%; categorized in this study as GOLD Grade 3 or 2011 GOLD D ${ }^{22}$ ), as well as patients with at least $12 \% \quad \mathrm{FEV}_{1}$ reversibility showed consistently higher responses in health status measured by SGRQ components and total score. In addition, individuals who were current smokers derived enhanced benefits with dual IND/GLY. These patient subgroups appear to be more likely to benefit from dual-bronchodilation for COPD, even though many would be classified in the current 2019 GOLD $^{4}$ categorization as Group B.

The BDI and TDI were developed to include major factors that affect a patient's experience of dyspnea, i.e., functional impairment, magnitude of task, and magnitude of effort. ${ }^{25}$ Certainly, shortness of breath based on physical tasks alone, as represented in the mMRC scale, does not indicate the full clinical impact of dyspnea. ${ }^{25}$ For example, a patient may perform certain tasks only by reducing the associated effort, and successful performance of a specific activity may not always be reflected in a person's functional capacity. Therefore, measurement of specific components of dyspnea provide a more detailed description than global ratings as obtained with the $\mathrm{mMRC}$ scale. Moreover, it is instructive to know how an individual treatment affects not only total dyspnea, but also specific components. In this study, we found that treatment with IND/GLY significantly improved all 


\section{Figure 5. Change From Baseline in Transition Dyspnea Index Total and Component Scores at Week 12}

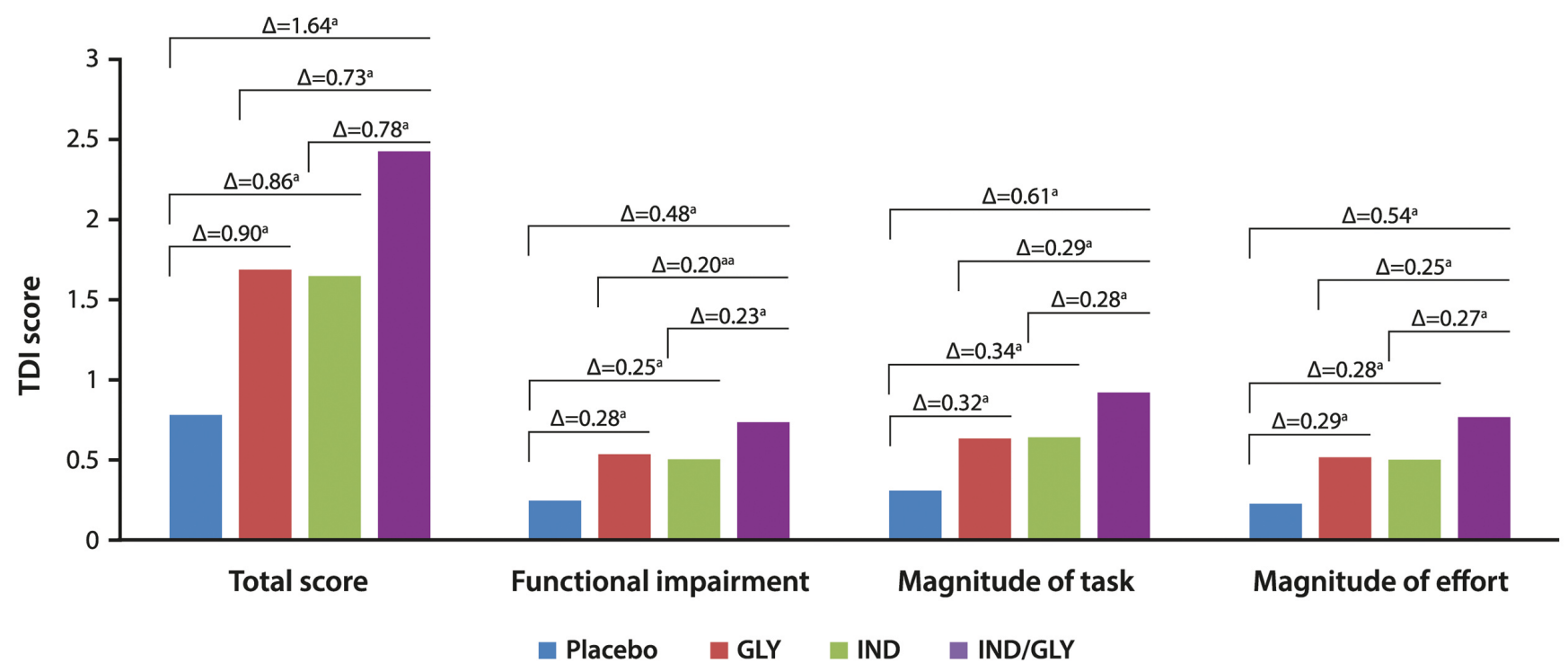

${ }^{\mathrm{a}} P<0.001$

aa $P=0.002$;

GLY=glycopyrrolate; $\mathrm{IND}=$ indacaterol

TDI components, functional impairment, magnitude of task, and magnitude of effort compared with IND, GLY, and placebo, suggesting that the overall improvement in the TDI total score is not driven by any one component. On average, patients with severe airflow limitation and GOLD 2011 Group D had TDI improvement more than double the MCID of the TDI total score and substantial improvement in each component. This suggests that IND/GLY not only improved the functional improvement but also the magnitude of task and effort.

There are several limitations to the pooled data of the FLIGHT studies. The studies were 12 weeks in length, which did not allow an assessment of the long-term effects of IND/GLY on HRQoL and dyspnea. A longer trial, with periodic SGRQ assessments, would enable us to better understand the effects of IND/GLY over time. Another limitation is that lung volumes, such as functional residual capacity and inspiratory capacity, were not measured. These measurements would help explain the improvements in HRQoL and dyspnea. In addition, IND/GLY, as a twice-daily bronchodilator, may potentially benefit night and early morning COPD symptoms, as well as daytime quality of life. But the FLIGHT studies did not assess any early morning or nighttime symptom questionnaires. Moreover, the time course of improvement in SGRQ and TDI was not assessed during the early weeks of the study, with week 12 outcomes reported in this analysis. The 2011 GOLD $^{22}$ risk categories (B, D) are likely driven by airflow limitation in this sample and the results should not be extended to exacerbation risk perceptions embedded in the original risk categories. In the subgroup analyses, interaction terms for treatment by subgroup showed no statistically significant difference, indicating that the results by subgroup should be interpreted with caution. The authors acknowledge that the overall impact of treatment accounts for the majority of change in SGRQ and TDI component scores; however, analysis by subgroup provides the opportunity to better characterize response among clinically meaningful groups of patients who might benefit most from dual bronchodilation. A further limitation is that the findings from our analysis are only applicable to the United States, where IND/ GLY 27.5/15.6 $\mu \mathrm{g}$ BID formulation is available. In comparison, outside the United States, IND/GLY is available as a once-daily formulation of indacaterol $110 \mu \mathrm{g}$ and glycopyrronium $50 \mu \mathrm{g}$. 


\section{Figure 6. Least Square Mean Differences in Change From Baseline in Transition Dyspnea Index Total and Component Scores ${ }^{a}$ in Indacaterol/Glycopyrrolate Versus Placebo ${ }^{\text {b }}$}

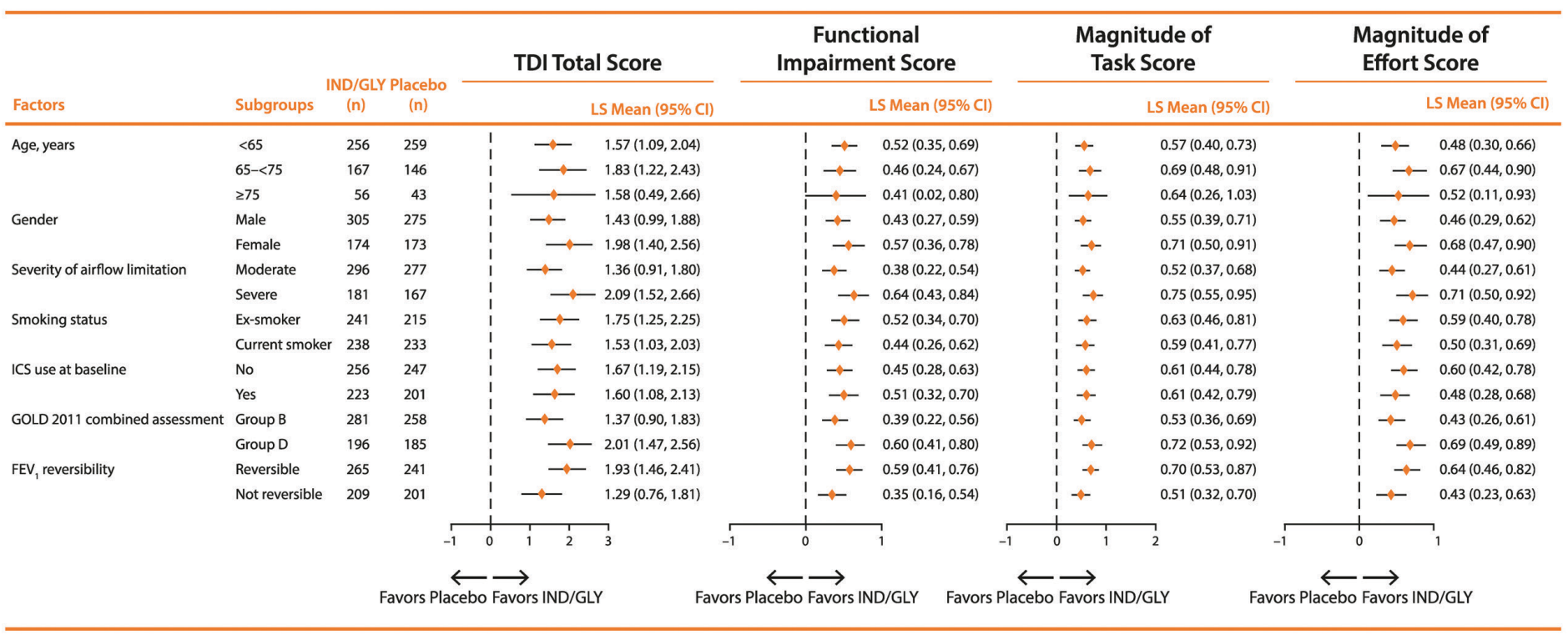

at week 12

bamong different patient subgroups

IND/GLY=indacaterol/glycopyrrolate; TDI=transition dyspnea index; LS=least square; CI=confidence interval;

ICS=inhaled corticosteroids; GOLD=Global initiative for chronic Obstructive Lung Disease; FEV 1 =forced expiratory volume in 1 second

\section{Conclusions}

In this pooled analysis of FLIGHT1 and FLIGHT2, IND/GLY BID resulted in significant improvements in total score and component scores of HRQoL and dyspnea as measured by SGRQ and TDI, respectively. IND/GLY may be a potential treatment option for patients with COPD.

\section{Acknowledgements}

The authors thank Pravin S. Kamble, PhD, for his role in the study and assistance with the manuscript. The authors also thank Karen G. Malley for programming support. These persons received no compensation apart from their usual salary for their contributions.

Author Contributions: DM and EK contributed to data collection. All authors contributed toward the study design, data analysis, interpretation of results and drafting and revising the manuscript, and agree to be accountable for all aspects of the work.

\section{Declaration of Interest}

Sunovion Pharmaceuticals Inc., provided funding for this research. Donald A. Mahler has participated in advisory boards for AstraZeneca, Boehringer Ingelheim, GlaxoSmithKline, Grifols, Sunovion, Theravance, and Trevi. He is on the speaker's bureau for AstraZeneca, Boehringer Ingelheim, and Sunovion. Edward M. Kerwin has participated in advisory boards, speaker panels, or received travel reimbursement for AstraZeneca, Amphastar, Boehringer Ingelheim, Mylan, Novartis, Pearl, Sunovion, Teva, and Theravance. He provided consulting services to Cipla and GlaxoSmithKline. Lindsey Murray is employed by Evidera, which provides consulting and other research services to pharmaceutical, device, government and nongovernment organizations. As an Evidera employee, she works with a variety of companies and organizations and is expressly prohibited from receiving any payment or honoraria directly from these organizations for services rendered. Carole Dembek is a full-time employee of Sunovion Pharmaceuticals Inc. 


\section{Figure 7. Odds Ratio for Achieving Minimum Clinically Important Difference in Transition Dyspnea Index Total Score in Indacaterol/Glycopyrrolate Versus Placebo ${ }^{a}$}

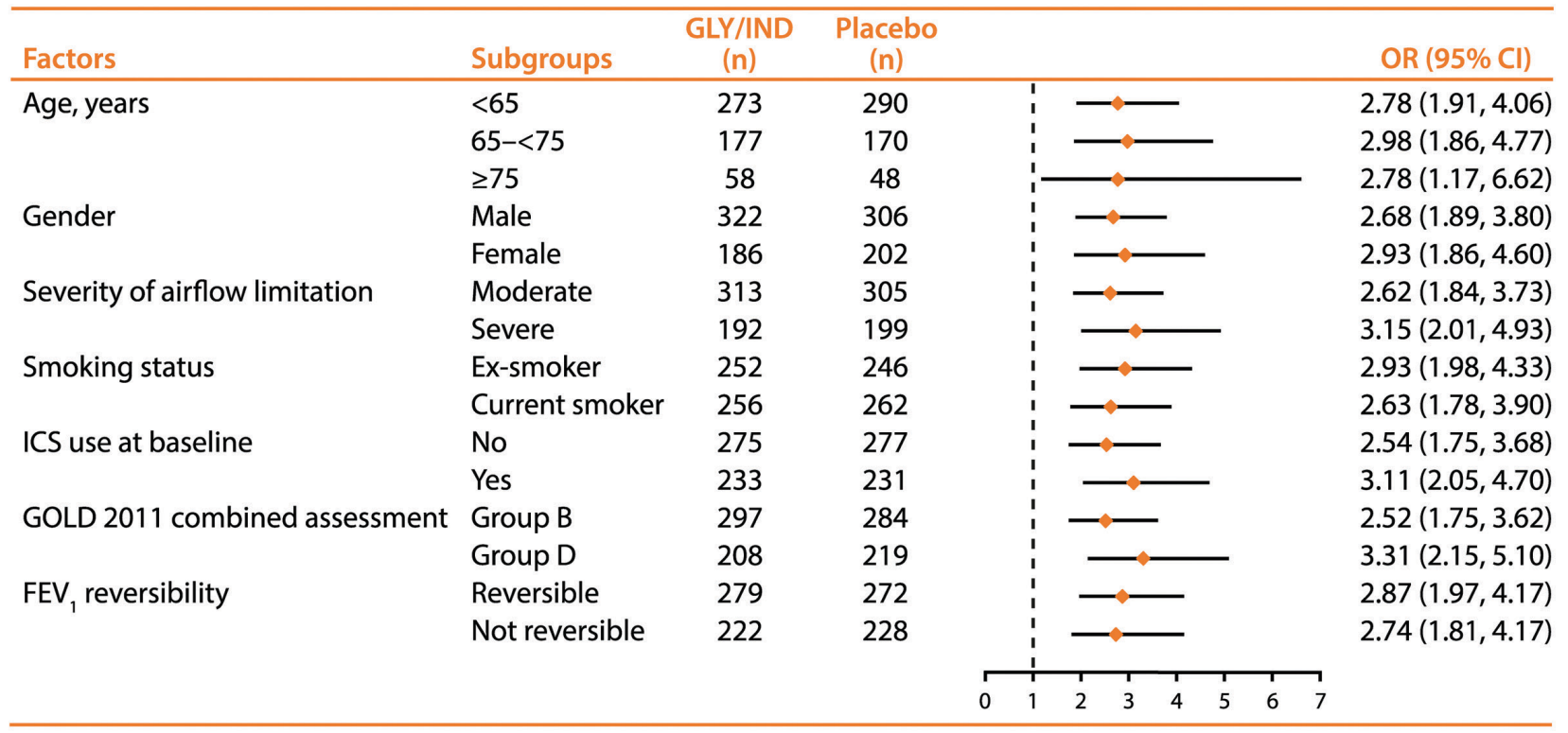

aamong different patient subgroups

IND/GLY= indacaterol/glycopyrrolate; OR=odds ratio; $\mathrm{CI}=$ confidence interval; $\mathrm{ICS}=$ inhaled corticosteroids; $\mathrm{GOLD}=\mathrm{Global}$ initiative for chronic Obstructive Lung Disease; $\mathrm{FEV}_{1}=$ forced expiratory volume in 1 second; 


\section{References}

1. Sullivan J, Pravosud V, Mannino DM, et al. National and state estimates of COPD morbidity and mortality-United States, 2014-2015. Chronic Obstr Pulm Dis. 2018;5(4):324-333. doi: https://doi.org/10.15326/jcopdf.5.4.2018.0157

2. Kochanek KD, Murphy SL, Xu JQ, Arias E. Mortality in the United States, 2016. NCHS Data Brief. 2017;293:1-8

3. Ford ES, Murphy LB, Khavjou O, Giles WH, Holt JB, Croft JB. Total and state-specific medical and absenteeism costs of COPD among adults aged $\geq 18$ years in the United States for 2010 and projections through 2020. Chest. 2015;147(1):31-45. doi: https://doi.org/10.1378/chest.14-0972

4. Global Initiative for Chronic Obstructive Lung Disease (GOLD). Global strategy for the diagnosis, management and prevention of COPD: 2019 Report. GOLD website. https://goldcopd.org/ gold-reports/. Published 2019. Accessed August 2019.

5. Greenlund KJ, Liu Y, Deokar AJ, Wheaton AG, Croft JB. Association of chronic obstructive pulmonary disease with increased confusion or memory loss and functional limitations among adults in 21 states, 2011 Behavioral Risk Factor Surveillance System. Prev Chronic Dis. 2016;13(E02):1-13. doi: https://doi.org/10.5888/pcd13.150428

6. Liu Y, Croft JB, Anderson LA, Wheaton AG, Presley-Cantrell L, Ford E. The association of chronic obstructive pulmonary disease, disability, engagement in social activities, and mortality among US adults aged 70 years or older, 1994-2006. Int J Chron Obstruct Pulmon Dis. 2014;9:75-83.

doi: https://doi.org/10.2147/COPD.S53676

7. Wheaton AG, Cunningham TJ, Ford ES, Croft JB. Employment and activity limitations among adults with chronic obstructive pulmonary disease-United States, 2013. MMRW Morb Mortal Wkly Rep. 2015;64(11):289-295

8. Kentson M, Todt K, Skargren E, et al. Factors associated with experience of fatigue, and functional imitations due to fatigue in patients with stable COPD. Ther Adv Respir Dis. 2016;10(5):410424. doi: https://doi.org/10.1177/1753465816661930

9. Seemungal TA, Donaldson GC, Paul EA, Bestall JC, Jeffries DJ, Wedzicha JA. Effect of exacerbation on quality of life in patients with chronic obstructive pulmonary disease. Am J Respir Crit Care Med. 1998;157(5):1418-1422.

doi: https://doi.org/10.1164/ajrccm.157.5.9709032

10. Blinderman CD, Homel P, Billings JA, Tennstedt S, Portenoy RK. Symptom distress and quality of life in patients with advanced chronic obstructive pulmonary disease. J Pain Symptom Manage. 2009;38(1):115-123.

doi: https://doi.org/10.1016/j.jpainsymman.2008.07.006

11. Jason C, Marks G, Buist S, et al. The impact of COPD on health status: findings from BOLD study. Eur Respir J. 2013;42:14721483. doi: https://doi.org/10.1183/09031936.00153712
12. UTIBRON ${ }^{\circledR}$ NEOHALER $^{\circledR}$ (indacaterol and glycopyrrolate) [package insert]. Marlborough, MA; Sunovion Pharmaceuticals Inc.; January 2018.

13. Mahler DA, Kerwin E, Ayers T, et al. FLIGHT1 and FLIGHT2: efficacy and safety of QVA149 (indacaterol/glycopyrrolate) versus its monocomponents and placebo in patients with chronic obstructive pulmonary disease. Am J Respir Crit Care Med. 2015;192(9):1068-1079.

doi: https://doi.org/10.1164/rccm.201505-10480C

14. ANORO $^{\circledR}$ ELLIPTA $^{\circledR}$ [Prescribing Information]. Research Triangle Park, NC; GlaxoSmithKline; October 2017.

15. Stiolto ${ }^{\circledR}$ Respimat $^{\circledR}$ [Prescribing Information]. Ridgefield, CT; Boehringer Ingelheim Pharmaceuticals, Inc.; May 2018.

16. Bevespi Aerosphere ${ }^{\circledR}$ [Prescribing Information]. Wilmington, DE; AstraZeneca Pharmaceuticals LP; June 2017

17. Duaklir ${ }^{\circledR}$ Pressair $^{\circledR}$ [Prescribing Information]. Morrisville, NC; Circassia Pharmaceuticals Inc.

18. Donohue JF, Maleki-Yazdi MR, Kilbride S, Mehta R, Kalberg C, Church A. Efficacy and safety of once-daily umeclidinium/ vilanterol 62.5/25 mcg in COPD. Respir Med. 2013;107(10):15381546. doi: https://doi.org/10.1016/j.rmed.2013.06.001

19. Decramer M, Anzueto A, Kerwin E, et al. Efficacy and safety of umeclidium plus vilanterol versus tiotropium, vilanterol, or umeclidium monotherapies over 24 weeks in patients with chronic obstructive pulmonary disease: results from two multicentre, blinded, randomised controlled trials. Lancet Respir Med. 2014;2:472-486. doi: https://doi.org/10.1016/S2213-2600(14)70065-7

20. Fergusen GT, Karpel J, Bennett N, et al. Effect of tiotropium and olodaterol on symptoms and patient-reported outcomes in patients with COPD: results from four randomised, double-blind studies. NPJ Prim Care Respir Med. 2017;27(1):7. doi: https://doi.org/10.1038/s41533-016-0002-x

21. D'Urzo AD, Rennard SI, Kerwin EM, Mergel V, Leselbaum AR, Caracta C. Efficacy and safety of fixed-dose combinations of aclidinium bromide/formoterol fumarate: the 24-week, randomized, placebo-controlled AUGMENT COPD study. Resp Res. 2014;15:123. doi: https://doi.org/10.1186/s12931-014-0123-0

22. Global Initiative for Chronic Obstructive Lung Disease (GOLD). Global strategy for the diagnosis, management and prevention of chronic obstructive pulmonary disease. 2011 Report. Meridian Health website.

https://corp.mhplan.com/ContentDocuments/default.aspx?x=1 F871MNPvi4C++SVsmEAO5szslTMvGaKPc6J5DF8qi+j57b3fsx LIFWfn9AzaO9nilBpalzhez7QL6bGCMv22w 
23. Jones PW, Quirk FH, Baveystock CM, Littlejohns P. A selfcomplete measure of health status for chronic airflow limitation. The St George's Respiratory Questionnaire. Am Rev Respir Dis. 1992; 145(6):1321-1327.

doi: https://doi.org/10.1164/ajrccm/145.6.1321

24. Jones PW. St George's Respiratory Questionnaire: MCID. COPD. 2005;2(1):75-79.

doi: https://doi.org/10.1081/COPD-200050513

25. Mahler DA, Weinberg DH, Wells CK, Feinstein AR. The measurement of dyspnea. Contents, interobserver agreement, and physiologic correlates of two new clinical indexes. Chest. 1984;85(6):751-758. doi: https://doi.org/10.1378/chest.85.6.751

26. Mahler DA, Horowitz MB. Clinical evaluation of exertional dyspnea. Clin Chest Med. 1994;15(2):259-269.

27. Mahler DA. Assessment and relief of dyspnoea. Monaldi Arch Chest Dis.1998;3(4):466-470.

28. Mahler DA, Witek TJ, Jr. The MCID of the transition dyspnea index is a total score of one unit. COPD. 2005;2(1):99-103.

doi: https://doi.org/10.1081/COPD-200050666 